\title{
High-speed extrusion of dilute Mg-Zn-Ca-Mn alloys and its effect on microstructure, texture and mechanical properties
}

\author{
M.G. Jiang ${ }^{\text {a, b }}$, C. Xu ${ }^{\text {c }}$, T. Nakata ${ }^{\text {c }}$, H. Yan ${ }^{a, *}$, R.S. Chen ${ }^{\text {a,* }}$, S. Kamado ${ }^{c}$ \\ ${ }^{a}$ The Group of Magnesium Alloys and Their Applications, Institute of Metal Research, \\ Chinese Academy of Sciences, 62 Wencui Road, Shenyang 110016, China \\ ${ }^{\mathrm{b}}$ University of Chinese Academy of Sciences, 19 Yuquan Road, Beijing 100049, China \\ ${ }^{c}$ Department of Mechanical Engineering, Nagaoka University of Technology, Nagaoka \\ 940-2188, Japan
}

\begin{abstract}
Three dilute Mg-Zn-Ca-Mn alloys were successfully extruded at $24 \mathrm{~m} / \mathrm{min}$ and the alloy with lowest $\mathrm{Zn}$ content $(0.21 \mathrm{wt} . \%)$ can even be extruded at $60 \mathrm{~m} / \mathrm{min}$ without any surface defects, which was ascribed to the thermally stable $\mathrm{Mg}_{2} \mathrm{Ca}$ phase and high solidus temperature $\left(\sim 620{ }^{\circ} \mathrm{C}\right)$. The alloys extruded at die-exit speed $\geq 6 \mathrm{~m} / \mathrm{min}$ showed a fully dynamically recrystallized (DRXed) microstructure and weak rare earth (RE) texture at the position between [2 $\overline{1} \overline{1} 4]$ and [2 $\overline{1} \overline{1} 2]$ parallel to the extrusion direction. Besides, fine $\mathrm{Mg}_{2} \mathrm{Ca}$ and $\alpha-\mathrm{Mn}$ particles dynamically precipitated during extrusion, acting as effective pinning obstacles against the DRXed grain growth via Zener drag effect. Due to the deformation temperature rise with increasing extrusion speeds, the grain size increased gradually, which can be understood from the relationship between DRXed grain size and Zener-Hollomon parameter. The RE texture contributed to high uniform elongation of $\sim 23 \%$, but the increased grain size $(>30 \mu \mathrm{m})$ deteriorated post-uniform elongation due to the prevalence of $\{10 \overline{1} 1\}$ contraction and $\{10 \overline{1} 1\}-\{10 \overline{1} 2\}$ double twins during post-uniform deformation.
\end{abstract}

Keywords : Magnesium alloy; Extrusion; Microstructure; Texture; Mechanical properties

\section{Introduction}

\footnotetext{
* Corresponding authors. Tel.: +86-24-23926646; Fax: +86-24-23894149. E-mail addresses: hyan@imr.ac.cn (H. Yan), rschen@imr.ac.cn (R.S. Chen)
} 
The slow extrusion speeds lead to high processing cost for magnesium $(\mathrm{Mg})$ extrusion, which becomes one of the most serious obstacles for the wide applications of wrought $\mathrm{Mg}$ alloys. It is reported that the extrusion speed of typical commercial AZ31 alloy is nearly two to five times slower than that of AA6063 aluminum (Al) alloy, and those containing higher alloy content such as AZ61 and ZK60 exhibit much poorer extrudability than AZ31 alloy [1-4]. The extrusion speed limit is generally associated with the solidus temperature of an alloy [5]. When local temperatures in the die land area exceed the solidus temperature during extrusion, incipient melting of the extrudate surface and subsequent cracking can occur [5]. Thus, improved extrudability of $\mathrm{Mg}$ alloys can be expected by reducing the level of alloy additions, particularly of those that reduce the solidus temperature. It has been reported that the maximum extrusion speeds can be raised up to die-exit speed of $72 \mathrm{~m} / \mathrm{min}$ in Mg-xAl-0.0Mn, Mg-xAl-1.0Zn and Mg-xZn-1.0Mn (wt.\%) alloys by lowering the Al or $\mathrm{Zn}$ content to $1.0 \mathrm{wt} . \%$ [6].

On the other hand, the extruded commercial $\mathrm{Mg}$ alloys tend to exhibit unsatisfactory formability and ductility at room temperature due to the formation of strong basal textures during hot extrusion [7-10]. Thus, weakening the basal texture intensity or changing the textures into some special ones can be an effective approach to improve the limited formability and ductility. In extrusion, the trace addition of rare earth (RE) elements in $\mathrm{Mg}$ alloys leads to the formation of a $<11 \overline{2} 1>$ component parallel to the extrusion direction (ED), which is commonly referred to as RE texture [11-15]. The RE texture makes the majority of grains well aligned for basal slip and $\{10 \overline{1} 2\}$ extension twinning during tensile deformation along the ED, resulting in an improved room temperature ductility $[11,12,16,17]$. Recently, it has been pointed out that $\mathrm{Ca}$ seems to be one feasible candidate to replace expensive $\mathrm{RE}$ elements, considering its large atomic radius equivalent to $\mathrm{RE}$ elements and relatively high solubility in $\mathrm{Mg}$ [18]. As expected, typical RE texture was obtained in binary $\mathrm{Mg}-\mathrm{Ca}$ alloys after hot extrusion [19,20]. A similar texture modification effect of Ca addition has also been observed in AZ31 [21], Mg-Mn-Ca [19] and Mg-Zn-Ca [22-24] alloys. Zhang et al. [22,23] have previously reported that $\mathrm{Ca}$ addition $(0.2,0.5 \mathrm{wt} . \%)$ to 
$\mathrm{Mg}-1.0 \mathrm{Zn}$ (wt.\%) alloy could effectively weaken and randomize the extrusion texture, thus contributing to high room temperature ductility of $35-45 \%$.

In our previous study [25], we newly developed dilute $\mathrm{Mg}-0.21 \mathrm{Zn}-0.30 \mathrm{Ca}-0.14 \mathrm{Mn}$ (wt.\%) alloy as low-cost wrought $\mathrm{Mg}$ alloy and achieved good balance of strength and ductility via slow-speed extrusion at different temperatures due to refined grains and weakened extrusion texture with RE texture component. Based on the previous studies on the extrudabiliy and effect of $\mathrm{Ca}$ on the extrusion texture, excellent extrudability and improved ductility could be expected in the dilute $\mathrm{Mg}-\mathrm{Zn}-\mathrm{Ca}-\mathrm{Mn}$ alloys with an optimized Ca content of $\sim 0.30$ wt.\%. In this study, therefore, three dilute $\mathrm{Mg}-\mathrm{Zn}-\mathrm{Ca}-\mathrm{Mn}$ alloys with different $\mathrm{Zn}$ content were prepared, and hot extrusion at die-exit speeds ranging from $6 \mathrm{~m} / \mathrm{min}$ to $60 \mathrm{~m} / \mathrm{min}$ was applied to the alloys to investigate the effect of extrusion speeds on the microstructure, texture and mechanical properties.

\section{Experimental procedures}

Three dilute Mg-Zn-Ca-Mn alloys with different Zn content denoted as Z02, Z05 and Z07 were examined in the present study. The chemical compositions were analyzed using inductively coupled plasma atomic emission spectroscopy (ICP-AES) and the results are listed in Table. 1. The alloys were prepared by resistance melting high purity $\mathrm{Mg}, \mathrm{Zn}, \mathrm{Mn}$ and $\mathrm{Mg}-30 \mathrm{wt} . \% \mathrm{Ca}$ master alloy in a steel crucible under the protection of a gas mixture of $\mathrm{SF}_{6}(1 \mathrm{Vol} . \%)$ and $\mathrm{CO}_{2}(99 \mathrm{Vol} . \%)$ and casting into a preheated steel mold with a dimension of $75 \mathrm{~mm} \times 180 \mathrm{~mm} \times 200 \mathrm{~mm}$. Billets of 43 $\mathrm{mm}$ in diameter and $35 \mathrm{~mm}$ in height were machined from the ingots and homogenized at $400{ }^{\circ} \mathrm{C}$ for $12 \mathrm{~h}$ followed by $450{ }^{\circ} \mathrm{C}$ for $12 \mathrm{~h}$ in an argon atmosphere, and finally quenched into water. Then these billets were extruded to bars (diameter of $9.6 \mathrm{~mm}$ ) using indirect extrusion method at $300{ }^{\circ} \mathrm{C}$ at die-exit speeds ranging from 6 $\mathrm{m} / \mathrm{min}$ to $60 \mathrm{~m} / \mathrm{min}$ under an extrusion ratio of 20 .

The microstructures were observed using optical microscope (OM, Olympus BX51M), electron back-scatter diffraction (EBSD) and transmission electron microscope (TEM, JEOL JEM-2100F) equipped with energy-dispersive X-ray 
spectroscopy (EDX) operating at $200 \mathrm{kV}$. EBSD observation was conducted on a JEOL JSM-7000F FE-SEM equipped with an EDAX-TSL EBSD system operating at $15 \mathrm{kV}$. Grain sizes and textures of the extruded samples were characterized by EBSD method and the data were analyzed with OIM Analysis software. To ensure statistical rigor, more than 2000 grains were examined for each condition. Thin foil specimens for the TEM observations were prepared by punching $3 \mathrm{~mm}$ in diameter discs, mechanical polishing and ion milling using a Gatan Precision Ion Polishing System (GATAN691). The thermal properties of the as-homogenized alloys were studied using differential scanning calorimetry (DSC, EXSTR6000) with temperatures ranging from $30{ }^{\circ} \mathrm{C}$ to $650{ }^{\circ} \mathrm{C}$ at a heating rate of $10{ }^{\circ} \mathrm{C} / \mathrm{min}$ under argon atmosphere. The mechanical properties were evaluated by room temperature tensile test at an initial strain rate of $1.0 \times 10^{-3} \mathrm{~s}^{-1}$ along the ED using round bar specimens with the diameter and gauge length of 4 and $20 \mathrm{~mm}$.

\section{Results and discussion}

Fig. 1 shows the extruded bar surfaces of the dilute alloys extruded at different die-exit speeds. After extrusion at $24 \mathrm{~m} / \mathrm{min}$, all the extrudates exhibited visually smooth and shiny surfaces. When the extrusion speed increased up to $60 \mathrm{~m} / \mathrm{min}$, good surface quality was obtained in Z02 alloy, while Z05 and Z07 alloys showed obvious surface defects. Compared to Z07 alloy with extensive surface cracks, Z05 alloy showed shallow surface cracks in local area with maximum crack depth of $\sim 300 \mu \mathrm{m}$.

It should be noted that incipient melting and thus cracking can occur during extrusion at temperatures well below the equilibrium solidus temperature of an alloy due to the presence of thermally unstable second phases [5]. For instance, the limited extrudability of commercial AZ31 alloy has been mainly attributed to the presence of $\mathrm{Mg}_{17} \mathrm{Al}_{12}$ eutectic phase with a low melting point of $438{ }^{\circ} \mathrm{C}$ [26] and $\mathrm{Mg}-\mathrm{Al}-\mathrm{Zn}$ ternary phase with an eutectic temperature of $338{ }^{\circ} \mathrm{C}$ [27]. Fig. 2 shows the distribution of second phase particles of the dilute alloys before extrusion. After homogenization, it can be observed that the second phase particles were drastically dissolved into $\mathrm{Mg}$ matrix, while sparse distribution of particles at grain boundaries 
(GBs) and within the grain interiors was still evident. According to our previous study [25], these particles were expected to be $\mathrm{Mg}_{2} \mathrm{Ca}$ phase, which has a high melting temperature of $715{ }^{\circ} \mathrm{C}$ [28]. DSC curves of the as-homogenized dilute alloys (Fig. 3) demonstrate that only one evident endothermic peak at $\sim 620{ }^{\circ} \mathrm{C}$ can be determined during the heating process, which is related to the melting of $\alpha-\mathrm{Mg}$ matrix. This suggests that the dilute alloys have much higher solidus temperature than AZ31 alloy $\left(570{ }^{\circ} \mathrm{C}[3]\right)$. Thus, the excellent extrudability of three dilute $\mathrm{Mg}-\mathrm{Zn}-\mathrm{Ca}-\mathrm{Mn}$ alloys can be mainly ascribed to the thermally stable $\mathrm{Mg}_{2} \mathrm{Ca}$ phase and high solidus temperatures of $\sim 620{ }^{\circ} \mathrm{C}$. In addition, Stanford et al. [29] reported that the localized Zn-enriched regions were likely to have a much lower local solidus temperature. As the intense deformation and frictional heating in the die and bearing surfaces causes substantial increases in temperature during high-speed extrusion, the actual extrusion temperature becomes much easier to reach the local solidus temperature of the $\mathrm{Zn}$-enriched regions, thus giving rise to hot cracking during extrusion. This may be the reason for the decreased extrudability with increasing $\mathrm{Zn}$ content in the dilute $\mathrm{Mg}-\mathrm{Zn}-\mathrm{Ca}-\mathrm{Mn}$ alloys.

Fig. 4 shows the inverse pole figure maps of the extruded dilute alloys. Three dilute alloys exhibited a fully dynamically recrystallized (DRXed) microstructure without any elongated unDRXed grains after extrusion at die-exit speed $\geq 6 \mathrm{~m} / \mathrm{min}$, and the DRXed grain size increased gradually with increasing extrusion speeds. Since the distribution and number fraction of second phase particles were almost the same in each alloy after extrusion at die-exit speed $\geq 6 \mathrm{~m} / \mathrm{min}$, the optical microstructures of the dilute alloys extruded at $24 \mathrm{~m} / \mathrm{min}$ were only presented in Fig. 5. It can be seen that the second phase particles with size of 1-3 $\mu \mathrm{m}$ distributed in the form of a strip along the ED. These particles were determined to be the $\mathrm{Mg}_{2} \mathrm{Ca}$ phase remained after homogenization. Besides, the enlarged etched optical microstructures in red rectangular regions show that fine second phase particles dynamically precipitated at DRXed GBs and within the grain interiors. These dynamic precipitates were further characterized using TEM and the results are presented in Fig. 6. Inspection of the TEM bright field (BF) and high-angle annular dark-field (HAADF) images clearly 
revealed that these precipitates had different sizes and shapes. In the corresponding EDX elemental mappings, the fine spherical particles of 5-20 nm were found to be rich in $\mathrm{Mn}$ and the relatively large spherical or plate-shaped particles of 20-400 nm were found to be enriched mainly with $\mathrm{Ca}$. Based on the EDX analysis results, therefore, the dynamic precipitates were expected to be the $\alpha-\mathrm{Mn}$ and $\mathrm{Mg}_{2} \mathrm{Ca}$ phases. As for Z07 alloy, few $\alpha$-Mn phase particles were observed due to the dilute Mn content (0.07 wt.\%).

In $\mathrm{Mg}$ alloys, the effect of large particles $(>1 \mu \mathrm{m})$ in promoting recrystallization via the mechanism of particle-stimulated nucleation (PSN) has been widely observed [30,31]. Although the dilute alloys contained large $\mathrm{Mg}_{2} \mathrm{Ca}$ particles of 1-3 $\mu \mathrm{m}$, as shown in Fig. 5, direct evidence of PSN was not detected during extrusion. On the other hand, it is known that finely distributed stable particles can prevent the grain growth by restricting grain boundary migration through the Zener drag (or Zener pinning) effect [32-34]. According to the classical Zener drag theory [35], the grain growth stagnates when the driving pressure for grain growth is balanced by the particle induced pinning pressure at certain average grain size. This grain size is named the Zener limited grain diameter $(D z)$, which can be classically expressed as [35]:

$D z \quad \frac{4 r}{3 f}$

where $f$ and $r$ are the volume fraction and average radius of pinning particles, respectively. Zener pinning is expected to occur if $D>D z$, but not if $D<D z[33,34]$. In this case, Z07 alloy was taken as a typical example to verify the pinning effect of different particles, including the fine dynamic precipitates and large $\mathrm{Mg}_{2} \mathrm{Ca}$ particles. The measured $f$ and $r$ of second phase particles, and calculated $D z$ for Z07 alloy after extrusion at $24 \mathrm{~m} / \mathrm{min}$ are summarized in Table. 2. Here, the average $f$ and $r$ values were determined by an Image-Pro Plus 6.0 software using low magnified TEM images for fine dynamic precipitates and optical microstructures for large $\mathrm{Mg}_{2} \mathrm{Ca}$ particles taken at three different locations. Apparently, the DRXed grain size (28.0-48.3 $\mu \mathrm{m})$ of the extruded Z07 alloy was far larger than the calculated Dz (5.8 
$\mu \mathrm{m})$ for fine dynamic precipitates, indicating that fine dynamically precipitated $\mathrm{Mg}_{2} \mathrm{Ca}$ and $\alpha-\mathrm{Mn}$ phases would become effective pinning obstacles for inhibiting the DRXed grain growth during extrusion via Zener drag effect.

Many studies have revealed that the DRXed grain size of $\mathrm{Mg}$ alloys is strongly dependent on the Zener-Hollomon parameter $\left(Z{ }^{\cdot} \exp (Q / R T)\right)$ [36-41], where ${ }^{\cdot}$ is the strain rate, $Q$ is the activation energy for the lattice diffusion of $\mathrm{Mg}, R$ is the gas constant and $T$ is the deformation temperature. The relationship between the DRXed grain size and the Zener-Hollomon parameter can be expressed in the form of [39-41]: $Z d_{D R X}^{m} \quad A$

where $d_{D R X}$ is the DRXed grain size, $m$ is the grain size exponent and $A$ is a constant. It is thus clear that the DRXed grain size increases with a decrease in $Z$ value, i.e. the grain size increases as the strain rate decreases and the temperature increases. In this case, however, the DRXed grain size increased with increasing extrusion speeds (Fig. 4), though the strain rate increased. This can be explained by an extensive rise in temperature due to the intense plastic deformation and friction during extrusion. The actual extrusion temperature could increase by more than $100{ }^{\circ} \mathrm{C}$ during extrusion at ram speed $\geq 5 \mathrm{~mm} / \mathrm{s}$ [42]. Xu et al. [40,41] have previously reported that the influence of the deformation temperature on the DRXed grain size is much stronger than that of the strain rate. Therefore, it is inferred that the dilute alloys showed increased DRX grain size due to a rise in deformation temperature with increasing extrusion speeds despite the Zener drag effect induced by pinning particles.

Fig. 7 shows the (0001) pole figures of the extruded dilute alloys. Three dilute alloys exhibited similar extrusion texture with maximum intensity of 2.8-3.9 and basal poles showing a large angle distribution of $\pm 60^{\circ}$ away from the transverse direction (TD) to the ED. Here, TD indicates the direction perpendicular to the ED. The corresponding inverse pole figures referring to the ED (Fig. 8) reveal that the texture components located at the position between [2 $\overline{1} \overline{1} 4]$ and [2 $\overline{1} \overline{1} 2]$ with intensity of 2.1-2.6. Compared to our previous study on the high-speed extrusion of Mg-1.58Zn-0.52Gd (wt.\%) alloy [16], three dilute alloys extruded at die-exit speed $\geq$ $6 \mathrm{~m} / \mathrm{min}$ showed similar weak RE texture at the position between [2 $\overline{1} \overline{1} 4]$ and [2$\overline{1} \overline{1} 2]$, 
in which the maximum intensity deviated approximately $45^{\circ}$ from [2 $\left.\overline{1} \overline{1} 0\right]$ parallel to the ED. This is completely different from the typical $<10 \overline{1} 0>$ fiber texture with $[10 \overline{1} 0]$ orientation parallel to the $\mathrm{ED}$, which is commonly observed in commercial $\mathrm{Mg}$ alloys after hot extrusion $[10,43]$. Upon the basis of the previous studies on the effect of $\mathrm{Ca}$ on the extrusion texture [18-24], as stated earlier, it is suggested that Ca addition might have a strong implication for the formation of RE texture in dilute $\mathrm{Mg}-\mathrm{Zn}-\mathrm{Ca}-\mathrm{Mn}$ alloys. However to date, there are no direct and sound evidences that could explain the underlying mechanism.

Fig. 9 shows the room temperature engineering stress-strain curves of the dilute alloys after extrusion at different die-exit speeds. After extrusion at $6 \mathrm{~m} / \mathrm{min}, \mathrm{Z} 07$ alloy showed superior mechanical properties to Z02 and Z05 alloys with tensile yield strength (TYS), ultimate tensile strength (UTS) and elongation of $108 \mathrm{MPa}, 220 \mathrm{MPa}$ and $37.0 \%$, respectively. For each alloy, it is evident that TYS and UTS decreased gradually with increasing extrusion speeds, whereas elongation decreased markedly when the extrusion speed increased up to $12 \mathrm{~m} / \mathrm{min}$ and remained almost constant at die-exit speed $\geq 12 \mathrm{~m} / \mathrm{min}$. It is noteworthy that three dilute alloys showed gradually increased TYS, UTS and elongation with increasing Zn content after extrusion at the same speed. Besides, nearly the same uniform elongation of $\sim 23 \%$ was obtained.

As evidenced from Fig. 9, three dilute alloys showed low yield strength less than $110 \mathrm{MPa}$ even after extrusion at $6 \mathrm{~m} / \mathrm{min}$. Generally, the yield strength $\left(\sigma_{\mathrm{s}} \quad \tau_{\text {basal }} / \mathrm{m}\right)$ depends on the critical resolved shear stress (CRSS) for basal slip $\left(\tau_{\text {basal }}\right)$ and the Schmid factor for basal slip (m $\cos \alpha \times \cos \beta$, where $\alpha$ and $\beta$ are the angles of tensile stress axis with respect to the optimal slip direction and basal plane normal, respectively), as the basal slip is the dominant deformation mode in $\mathrm{Mg}$ alloys at room temperature. For three dilute alloys with RE texture, as shown in Fig. 8, the angle between tensile stress axis (ED) and basal plane normal (c-axis) varied from 22-52 . Assuming that the angles $\alpha$ and $\beta$ are in the same plane, $\alpha$ and $\beta$ should be complementary $\left(\alpha+\beta \quad 90^{\circ}\right)$. Hence, the Schmid factor for basal slip can be calculated to be $0.35-0.50$. Fig. 10 shows the Schmid factor distribution histograms for basal slip analyzed by EBSD. Three dilute alloys showed high average Schmid 
factor for basal slip of $0.36-0.40$, which falls within the calculated range. This indicates that basal slip dislocations were favorably operated in most grains when tension along the ED, thereby leading to the low yield strength for three dilute alloys. In addition to the texture effect, yield strength can be also affected by the grain size [44], second phase [45] and solute atoms [46], etc. For each alloy, as descried above, the distribution and number fraction of the second phase were almost the same irrespective of the extrusion speed (Fig. 5). According to the Hall-Petch relation, therefore, obvious yield strength drop was the result of the increased grain size with increasing extrusion speeds. On the other hand, three dilute alloys showed increased yield strength with increasing $\mathrm{Zn}$ content after extrusion at the same speed. Considering the similar texture and grain size, it is inferred that the second phase and solute atoms have larger effect on the enhanced yield strength. Furthermore, Z05 and Z07 alloys showed nearly the same density of dynamic precipitates (Fig. 5), whereas Z07 alloy showed higher yield strength than Z05 alloy. This suggests that the solute atoms play dominant roles in the yield strength based on the well-known solid solution strengthening [46]. Since the $\mathrm{Ca}$ and $\mathrm{Mn}$ atoms are largely consumed by the formation of $\mathrm{Mg}_{2} \mathrm{Ca}$ and $\alpha-\mathrm{Mn}$ phases, respectively, $\mathrm{Zn}$ solute atoms mainly contribute to the enhanced yield strength. Therefore, optimization of $\mathrm{Zn}$ content is of great significance for designing high-speed extrudable dilute $\mathrm{Mg}-\mathrm{Zn}-\mathrm{Ca}-\mathrm{Mn}$ alloys, because increased $\mathrm{Zn}$ content is favorable for enhancing the strength, but deteriorates the extrudability at the same time.

Fig. 11 shows the optical microstructures of fractured tensile specimens of the extruded dilute alloys. High density of twins can be observed in all specimens and many micro-cracks initiated along the twins as indicated by red arrows. Additionally, no crack initiation was observed at the large $\mathrm{Mg}_{2} \mathrm{Ca}$ particles (1-3 $\left.\mu \mathrm{m}\right)$, which distributed in the form of a strip along the ED as shown in Fig. 5. This suggests a strong relation between the twinning behavior and the fracture mechanism during tension along the ED. As for the extruded AZ31 alloy with typical basal texture, $\{10 \overline{1} 1\}$ contraction and $\{10 \overline{1} 1\}-\{10 \overline{1} 2\}$ double twins tend to easily form when tension along the ED because the c-axis of most grains is perpendicular to the tensile 
stress $[7,11]$. The formation of these twins generally leads to rapid flow localization and causes early shear failure due to combined effect of strain softening and localized twin-sized voids formation [47-50]. But for the dilute alloys with RE texture in this case, as discussed in our previous study [16], both basal slip and $\{10 \overline{1} 2\}$ extension twins became dominant deformation modes when tension along the ED and their interaction led to the enhanced strain hardening, effectively delaying the onset of plastic instability. Besides, the activation of $\{10 \overline{1} 2\}$ extension twins and their growth, as well as basal slip activity, could gradually alter the texture from non-basal to basal component during uniform tensile deformation [17,51]. For this reason, the majority of grains would become favorable orientations for $\{10 \overline{1} 1\}$ contraction and $\{10 \overline{1} 1\}-\{10 \overline{1} 2\}$ double twins during post-uniform deformation. As the CRSS for twinning decreased with increasing grain size [50,52], these twins can be more easily activated in large grains, consequently leading to large incompatibilities at the parent-twin interfaces and thus deteriorating post-uniform elongation. Previous studies have revealed that uniform elongation is strongly correlated with the texture and increased grain size significantly decreases the post-uniform elongation [53-55]. Therefore, it is reasonable to believe that the extruded dilute alloys showed nearly the same uniform elongation due to their similar RE texture, but the increased grain size with increasing extrusion speeds deteriorated the post-uniform elongation due to the prevalence of $\{10 \overline{1} 1\}$ contraction and $\{10 \overline{1} 1\}-\{10 \overline{1} 2\}$ double twins. As a result, the total elongation decreased markedly in each alloy when the grain size increased larger than $30 \mu \mathrm{m}$.

In this study, three dilute alloys were successfully extruded at $24 \mathrm{~m} / \mathrm{min}$ and Z02 alloy can even be extruded at $60 \mathrm{~m} / \mathrm{min}$ without any surface defects, suggesting the better extrudability than commercial AZ31 alloy [16]. However, they showed decreased yield strength $(<100 \mathrm{MPa})$ and ductility $(<30 \%)$ with increasing extrusion speeds as a result of the increased DRXed grain size. If the DRXed grain growth can be further controlled during extrusion $(<30 \mu \mathrm{m})$, the dilute alloys can be expected to be a promising candidate as industrially available wrought $\mathrm{Mg}$ alloy with superior extrudability and ductility. Therefore, future study on the dilute $\mathrm{Mg}-\mathrm{Zn}-\mathrm{Ca}-\mathrm{Mn}$ alloys 
needs to focus on how to impede the grain growth during high-speed extrusion and further improve the mechanical properties through various methods such as artificial cooling during extrusion [56] and precipitation of Guinier Preston (G.P.) zones by aging after extrusion [57].

\section{Conclusions}

In summary, three dilute Mg-Zn-Ca-Mn alloys were successfully extruded at 24 $\mathrm{m} / \mathrm{min}$ and Z02 alloy can even be extruded at high die-exit speed of $60 \mathrm{~m} / \mathrm{min}$ without any surface defects, which was ascribed to the thermally stable $\mathrm{Mg}_{2} \mathrm{Ca}$ phase and high solidus temperature $\left(\sim 620^{\circ} \mathrm{C}\right)$. After extrusion at die-exit speed $\geq 6 \mathrm{~m} / \mathrm{min}$, the dilute alloys showed a fully DRXed microstructure and weak RE texture at the position between [2 $\overline{1} \overline{1} 4]$ and [2 $\overline{1} \overline{1} 2$ ] parallel to the ED. Besides, fine $\mathrm{Mg}_{2} \mathrm{Ca}$ and $\alpha-\mathrm{Mn}$ particles dynamically precipitated during extrusion, acting as effective pinning obstacles for inhibiting the DRXed grain growth via Zener drag effect. Despite these pinning particles, the grain size gradually increased with increasing extrusion speeds because of the deformation temperature rise generated by plastic deformation and friction during extrusion. This can be understood by the relationship between the DRXed grain size and the Zener-Hollomon parameter. Due to the similar RE texture, which was favorable for basal slip and $\{10 \overline{1} 2\}$ extension twins, three dilute alloys showed nearly the same high uniform elongation of $\sim 23 \%$. The increased grain size (> $30 \mu \mathrm{m})$ was detrimental to the post-uniform elongation due to the prevalence of $\{10 \overline{1} 1\}$ contraction and $\{10 \overline{1} 1\}-\{10 \overline{1} 2\}$ double twins during post-uniform deformation. Therefore if the grain growth can be further controlled during extrusion, dilute $\mathrm{Mg}-\mathrm{Zn}-\mathrm{Ca}-\mathrm{Mn}$ alloys have great potential as high-speed extrudable wrought $\mathrm{Mg}$ alloy with improved ductility.

\section{Acknowledgments}

The authors gratefully acknowledge the financial supports from the State Key Program of National Natural Science of China (No. 51531002), National Natural Science Foundation of China (NSFC, No. 51601193 and 51301173), National Key Research and Development Program of China (No. 2016YFB0301104), National Basic Research Program of China (973 Program, No. 2013CB632202), 
JST, Advanced Low Carbon Technology Research and Development Program (ALC A, No. 12102886) and JSPS, Grant-in-Aid for Young Scientists (B) (No. 16K18266). 


\section{References}

[1] C. Davies, M. Barnett, Expanding the extrusion limits of wrought magnesium alloys, JOM, 56 (2004) 22-24.

[2] C. Bettles, M. Gibson, Current wrought magnesium alloys: strengths and weaknesses, JOM, 57 (2005) 46-49.

[3] D.L. Atwell, M.R. Barnett, Extrusion limits of magnesium alloys, Metall. Mater. Trans. A, 38 (2007) 3032-3041.

[4] M. Easton, A. Beer, M. Barnett, C. Davies, G. Dunlop, Y. Durandet, S. Blacket, T. Hilditch, P. Beggs, Magnesium alloy applications in automotive structures, JOM, 60 (2008) 57-62.

[5] C. Bettles, M. Barnett, Advances in wrought magnesium alloys: Fundamentals of processing, properties and applications, Elsevier, Woodhead Publishing, Philadelphia, 2012.

[6] J.F. Lass, F.W. Bach, M. Schaper, Adapted extrusion technology for magnesium alloys, Magnesium Technology 2005, TMS, (2005) 159-164.

[7] N. Stanford, M. Barnett, Effect of composition on the texture and deformation behaviour of wrought Mg alloys, Scr. Mater. 58 (2008) 179-182.

[8] Y. Chino, K. Kimura, M. Hakamada, M. Mabuchi, Mechanical anisotropy due to twinning in an extruded AZ31 Mg alloy, Mater. Sci. Eng. A 485 (2008) 311-317.

[9] S. Kleiner, P. Uggowitzer, Mechanical anisotropy of extruded Mg-6\% Al-1\% Zn alloy, Mater. Sci. Eng. A 379 (2004) 258-263.

[10] T. Bhattacharjee, T. Nakata, T. Sasaki, S. Kamado, K. Hono, Effect of microalloyed $\mathrm{Zr}$ on an extruded microstructure of $\mathrm{Mg}-6.2 \mathrm{Zn}$ based alloys, Scr. Mater. 90-91 (2014) 37-40.

[11] N. Stanford, M.R. Barnett, The origin of "rare earth" texture development in extruded Mg-based alloys and its effect on tensile ductility, Mater. Sci. Eng. A 496 (2008) 399-408.

[12] N. Stanford, D. Atwell, A. Beer, C. Davies, M. Barnett, Effect of microalloying with rare-earth elements on the texture of extruded magnesium-based alloys, Scr. Mater. 59 (2008) 772-775.

[13] A.A. Luo, R.K. Mishra, A.K. Sachdev, High-ductility magnesium-zinc-cerium extrusion alloys, Scr. Mater. 64 (2011) 410-413.

[14] J.P. Hadorn, T.T. Sasaki, T. Nakata, T. Ohkubo, S. Kamado, K. Hono, Solute clustering and grain boundary segregation in extruded dilute $\mathrm{Mg}-\mathrm{Gd}$ alloys, Scr. Mater. 93 (2014) 28-31.

[15] W.X. Wu, L. Jin, Z.Y. Zhang, W.J. Ding, J. Dong, Grain growth and texture evolution during annealing in an indirect-extruded Mg-1Gd alloy, J. Alloys Compd. 585 (2014) 111-119.

[16] M.G. Jiang, C. Xu, T. Nakata, H. Yan, R.S. Chen, S. Kamado, Rare earth texture and improved ductility in a Mg-Zn-Gd alloy after high-speed extrusion, Mater. Sci. Eng. A 667 (2016) 233-239.

[17] N. Zhou, Z. Zhang, L. Jin, J. Dong, B. Chen, W. Ding, Ductility improvement by twinning and twin-slip interaction in a Mg-Y alloy, Mater. Des. 56 (2014) 966-974. 
[18] I.-H. Jung, M. Sanjari, J. Kim, S. Yue, Role of RE in the deformation and recrystallization of $\mathrm{Mg}$ alloy and a new alloy design concept for Mg-RE alloys, Scr. Mater. 102 (2015) 1-6.

[19] N. Stanford, The effect of calcium on the texture, microstructure and mechanical properties of extruded Mg-Mn-Ca alloys, Mater. Sci. Eng. A 528 (2010) 314-322.

[20] T. Wang, L. Jiang, R.K. Mishra, J.J. Jonas, Effect of Ca Addition on the Intensity of the Rare Earth Texture Component in Extruded Magnesium Alloys, Metall. Mater. Trans. A 45 (2014) 4698-4709.

[21] T. Laser, C. Hartig, M. Nürnberg, D. Letzig, R. Bormann, The influence of calcium and cerium mischmetal on the microstructural evolution of $\mathrm{Mg}-3 \mathrm{Al}-1 \mathrm{Zn}$ during extrusion and resulting mechanical properties, Acta Mater. 56 (2008) 2791-2798.

[22] B.P. Zhang, L. Geng, L.J. Huang, X.X. Zhang, C.C. Dong, Enhanced mechanical properties in fine-grained $\mathrm{Mg}-1.0 \mathrm{Zn}-0.5 \mathrm{Ca}$ alloys prepared by extrusion at different temperatures, Scr. Mater. 63 (2010) 1024-1027.

[23] B. Zhang, Y. Wang, L. Geng, C. Lu, Effects of calcium on texture and mechanical properties of hot-extruded Mg-Zn-Ca alloys, Mater. Sci. Eng. A 539 (2012) 56-60.

[24] H. Ding, X. Shi, Y. Wang, G. Cheng, S. Kamado, Texture weakening and ductility variation of Mg-2Zn alloy with CA or RE addition, Mater. Sci. Eng. A 645 (2015) 196-204.

[25] M.G. Jiang, C. Xu, T. Nakata, H. Yan, R.S. Chen, S. Kamado, Development of dilute $\mathrm{Mg}-\mathrm{Zn}-\mathrm{Ca}-\mathrm{Mn}$ alloy with high performance via extrusion, J. Alloys Compd. 668 (2016) 13-21.

[26] T. Nakata, T. Mezaki, R. Ajima, C. Xu, K. Oh-ishi, K. Shimizu, S. Hanaki, T.T. Sasaki, K. Hono, S. Kamado, High-speed extrusion of heat-treatable Mg-Al-Ca-Mn dilute alloy, Scr. Mater. 101 (2015) 28-31.

[27] A. Luo, C. Zhang, A. Sachdev, Effect of eutectic temperature on the extrudability of magnesium-aluminum alloys, Scr. Mater. 66 (2012) 491-494.

[28] A. Nayeb-Hashemi, Phase diagrams of binary magnesium alloys, ASM International, Metals Park, Ohio 44073, USA, 1988. 370, (1988).

[29] N. Stanford, D. Atwell, The effect of Mn-rich precipitates on the strength of AZ31 extrudates, Metall. Mater. Trans. A 44 (2013) 4830-4843.

[30] J. Robson, D. Henry, B. Davis, Particle effects on recrystallization in magnesium-manganese alloys: Particle-stimulated nucleation, Acta Mater. 57 (2009) 2739-2747.

[31] T. Al-Samman, Modification of texture and microstructure of magnesium alloy extrusions by particle-stimulated recrystallization, Mater. Sci. Eng. A 560 (2013) 561-566.

[32] J. Robson, D. Henry, B. Davis, Particle effects on recrystallization in magnesium-manganese alloys: Particle pinning, Mater. Sci. Eng. A 528 (2011) 4239-4247.

[33] J.P. Hadorn, K. Hantzsche, S. Yi, J. Bohlen, D. Letzig, S.R. Agnew, Effects of solute and second-phase particles on the texture of $\mathrm{Nd}$-containing $\mathrm{Mg}$ alloys, Metall. 
Mater. Trans. A 43 (2012) 1363-1375.

[34] J.P. Hadorn, R.P. Mulay, K. Hantzsche, S. Yi, J. Bohlen, D. Letzig, S.R. Agnew, Texture Weakening Effects in Ce-Containing Mg Alloys, Metall. Mater. Trans. A 44 (2013) 1566-1576.

[35] A. Rollett, F. Humphreys, G.S. Rohrer, M. Hatherly, Recrystallization and related annealing phenomena, Elsevier, 2004.

[36] M. Mabuchi, K. Kubota, K. Higashi, New Recycling Process by Extrusion for Machined Chips of AZ91 Magnesium and Mechanical Properties of Extruded Bars, Mater. Trans. A 36 (1995) 1249-1254.

[37] A. Galiyev, R. Kaibyshev, G. Gottstein, Correlation of plastic deformation and dynamic recrystallization in magnesium alloy Zk60, Acta Mater. 49 (2001) 1199-1207.

[38] M. Myshlyaev, H. McQueen, A. Mwembela, E. Konopleva, Twinning, dynamic recovery and recrystallization in hot worked Mg-Al-Zn alloy, Mater. Sci. Eng. A 337 (2002) 121-133.

[39] C.I. Chang, C.J. Lee, J.C. Huang, Relationship between grain size and Zener-Holloman parameter during friction stir processing in AZ31 Mg alloys, Scr. Mater. 51 (2004) 509-514.

[40] S. Xu, N. Matsumoto, S. Kamado, T. Honma, Y. Kojima, Dynamic microstructural changes in Mg-9Al-1Zn alloy during hot compression, Scr. Mater. 61 (2009) 249-252.

[41] S.W. Xu, S. Kamado, T. Honma, Recrystallization mechanism and the relationship between grain size and Zener-Hollomon parameter of $\mathrm{Mg}-\mathrm{Al}-\mathrm{Zn}-\mathrm{Ca}$ alloys during hot compression, Scr. Mater. 63 (2010) 293-296.

[42] R.Y. Lapovok, M.R. Barnett, C.H.J. Davies, Construction of extrusion limit diagram for AZ31 magnesium alloy by FE simulation, J. Mater. Process. Technol. 146 (2004) 408-414.

[43] S. Yi, H.-G. Brokmeier, D. Letzig, Microstructural evolution during the annealing of an extruded AZ31 magnesium alloy, J. Alloys Compd. 506 (2010) 364-371.

[44] I. Toda-Caraballo, E.I. Galindo-Nava, P.E.J. Rivera-Díaz-del-Castillo, Understanding the factors influencing yield strength on Mg alloys, Acta Mater. 75 (2014) 287-296.

[45] C.L. Mendis, K. Oh-ishi, Y. Kawamura, T. Honma, S. Kamado, K. Hono, Precipitation-hardenable Mg-2.4Zn-0.1Ag-0.1Ca-0.16Zr (at.\%) wrought magnesium alloy, Acta Mater. 57 (2009) 749-760.

[46] L. Gao, R.S. Chen, E.H. Han, Effects of rare-earth elements Gd and Y on the solid solution strengthening of Mg alloys, J. Alloys Compd. 481 (2009) 379-384.

[47] J. Koike, Enhanced deformation mechanisms by anisotropic plasticity in polycrystalline $\mathrm{Mg}$ alloys at room temperature, Metall. Mater. Trans. A 36 (2005) 1689-1696.

[48] M.R. Barnett, Twinning and the ductility of magnesium alloys Part II. "Contraction" twins, Mater. Sci. Eng. A 464 (2007) 8-16.

[49] P. Cizek, M.R. Barnett, Characteristics of the contraction twins formed close to 
the fracture surface in $\mathrm{Mg}-3 \mathrm{Al}-1 \mathrm{Zn}$ alloy deformed in tension, Scr. Mater. 59 (2008) 959-962.

[50] A. Jain, O. Duygulu, D. Brown, C. Tomé, S. Agnew, Grain size effects on the tensile properties and deformation mechanisms of a magnesium alloy, AZ31B, sheet, Mater. Sci. Eng. A 486 (2008) 545-555.

[51] H. Yan, S. Xu, R. Chen, S. Kamado, T. Honma, E. Han, Activation of $\{10-12\}$ twinning and basal slip in a high ductile $\mathrm{Mg}-2.0 \mathrm{Zn}-0.8 \mathrm{Gd}$ rolled sheet with a non-basal texture during tensile deformation at room temperature, J. Alloys Compd. 566 (2013) 98-107.

[52] S.H. Park, S.-H. Kim, H.S. Kim, J. Yoon, B.S. You, High-speed indirect extrusion of $\mathrm{Mg}-\mathrm{Sn}-\mathrm{Al}-\mathrm{Zn}$ alloy and its influence on microstructure and mechanical properties, J. Alloys Compd. 667 (2016) 170-177.

[53] W. Chen, X. Wang, E. Wang, Z. Liu, L. Hu, Texture dependence of uniform elongation for a magnesium alloy, Scr. Mater. 67 (2012) 858-861.

[54] D. Wu, R.S. Chen, W.N. Tang, E.H. Han, Influence of texture and grain size on the room-temperature ductility and tensile behavior in a Mg-Gd-Zn alloy processed by rolling and forging, Mater. Des. 41 (2012) 306-313.

[55] B. Shi, R. Chen, W. Ke, Influence of grain size on the tensile ductility and deformation modes of rolled Mg-1.02 wt.\% Zn alloy, J. Magnes. Alloys 1 (2013) 210-216.

[56] S.H. Park, S.-H. Kim, H.S. Kim, B.S. You, Improved strength of Mg alloy extruded at high speed with artificial cooling, J. Alloys Compd. 648 (2015) 615-621.

[57] K. Oh-ishi, R. Watanabe, C.L. Mendis, K. Hono, Age-hardening response of $\mathrm{Mg}-0.3$ at.\%Ca alloys with different $\mathrm{Zn}$ contents, Mater. Sci. Eng. A 526 (2009) 177-184. 


\section{Table Captions}

Table.1 Analyzed chemical compositions of the investigated alloys (wt. \%).

Table. 2 The measured volume fraction $(f)$ and average radius $(r)$ of second phase particles, and calculated Zener limited grain diameter $(D z)$ for Z07 alloy after extrusion at $24 \mathrm{~m} / \mathrm{min}$. 


\section{Figure Captions}

Fig. 1 Extruded bar surfaces of the dilute alloys extruded at different die-exit speeds.

Fig. 2 Optical microstructures of the dilute alloys showing the distribution of second phase particles before extrusion.

Fig. 3 DSC curves of the as-homogenized dilute alloys.

Fig. 4 Inverse pole figure maps of the extruded dilute alloys.

Fig. 5 Optical microstructures of the dilute alloys showing the distribution of second phase particles after extrusion at $24 \mathrm{~m} / \mathrm{min}$. Here, etched optical microstructures in red rectangular regions show fine dynamic precipitates distributing at DRXed GBs and within the grain interiors.

Fig. 6 TEM observation results of dynamic precipitates in the dilute alloys extruded at $24 \mathrm{~m} / \mathrm{min}$ : HAADF images and the corresponding EDX elemental mappings of Z02 and Z05 alloys and TEM BF images of Z07 alloy.

Fig. 7 (0001) pole figures of the extruded dilute alloys.

Fig. 8 Inverse pole figures referring to the ED of the extruded dilute alloys.

Fig. 9 Room temperature engineering stress-strain curves of the extruded dilute alloys.

Fig. $10(0001)<11 \overline{2} 0>$ basal slip Schmid factor distribution histograms of the extruded dilute alloys when the tensile stress is applied along the ED. 
Fig. 11 Optical microstructures of fractured tensile specimens of the extruded dilute alloys. The red arrows indicate the microcracks initiated along the twins. 
Fig. 1

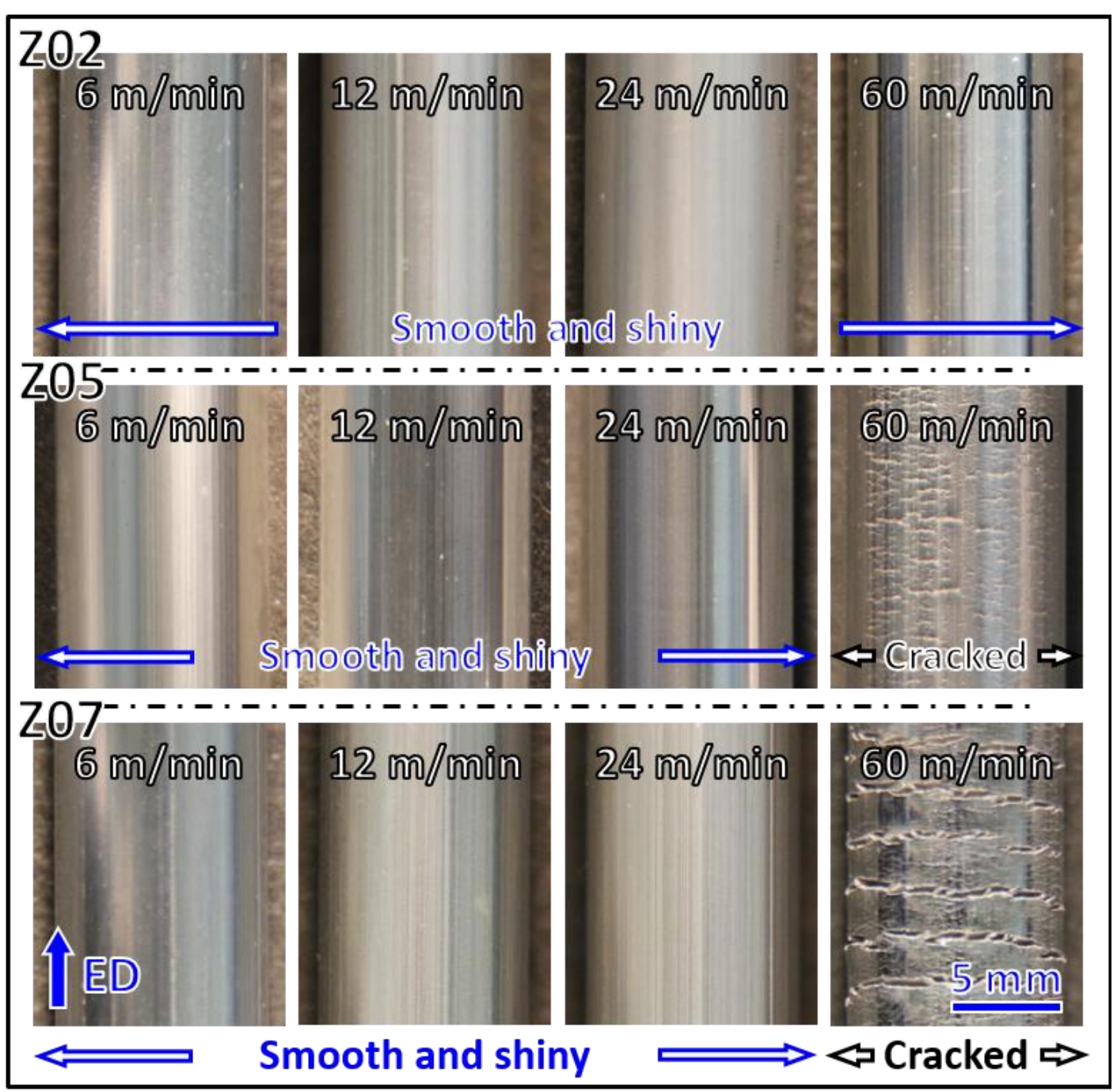

Fig. 1 Extruded bar surfaces of the dilute alloys extruded at different die-exit speeds. 
Fig. 2

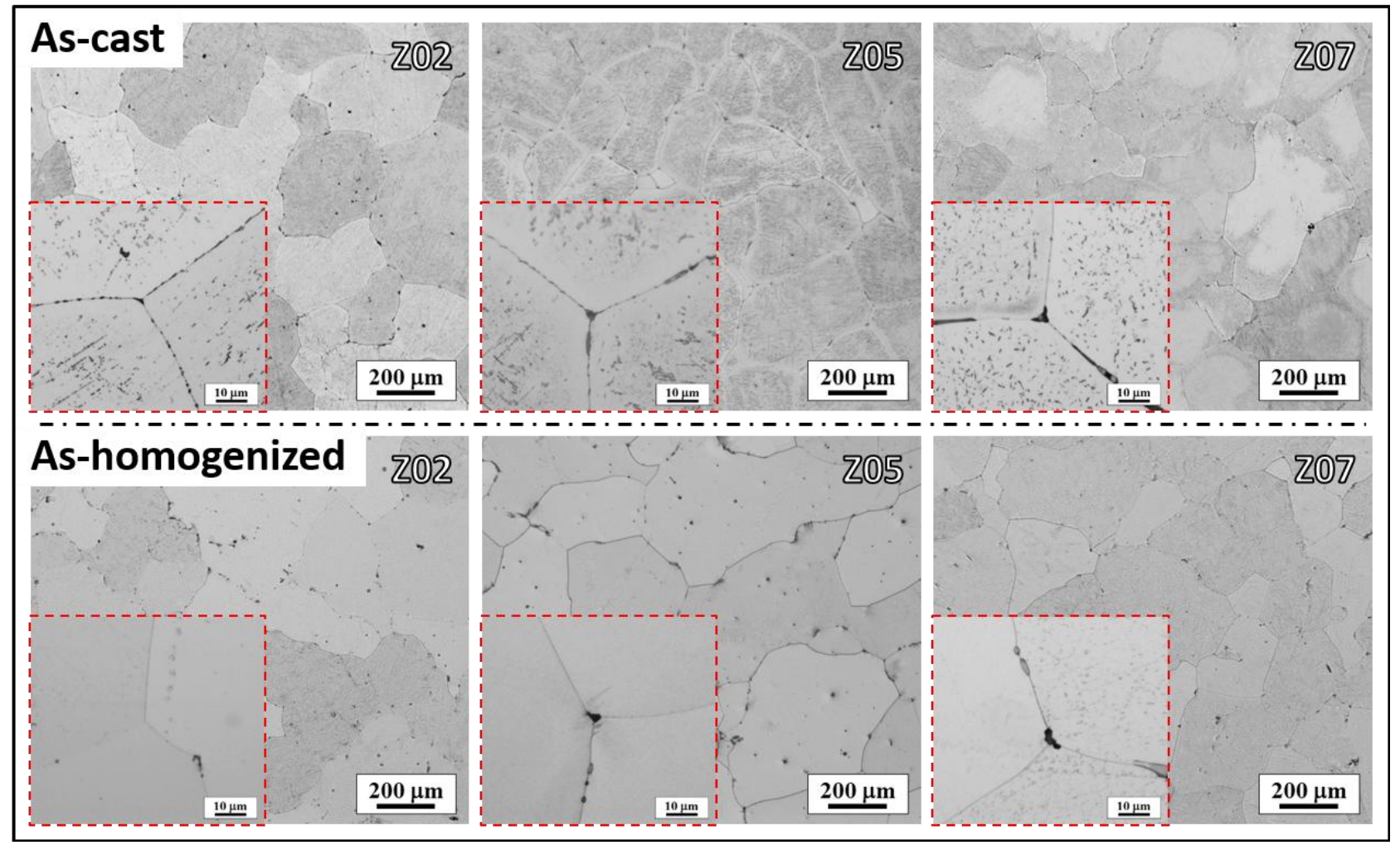

Fig. 2 Optical microstructures of the dilute alloys showing the distribution of second phase particles before extrusion.

Fig. 3

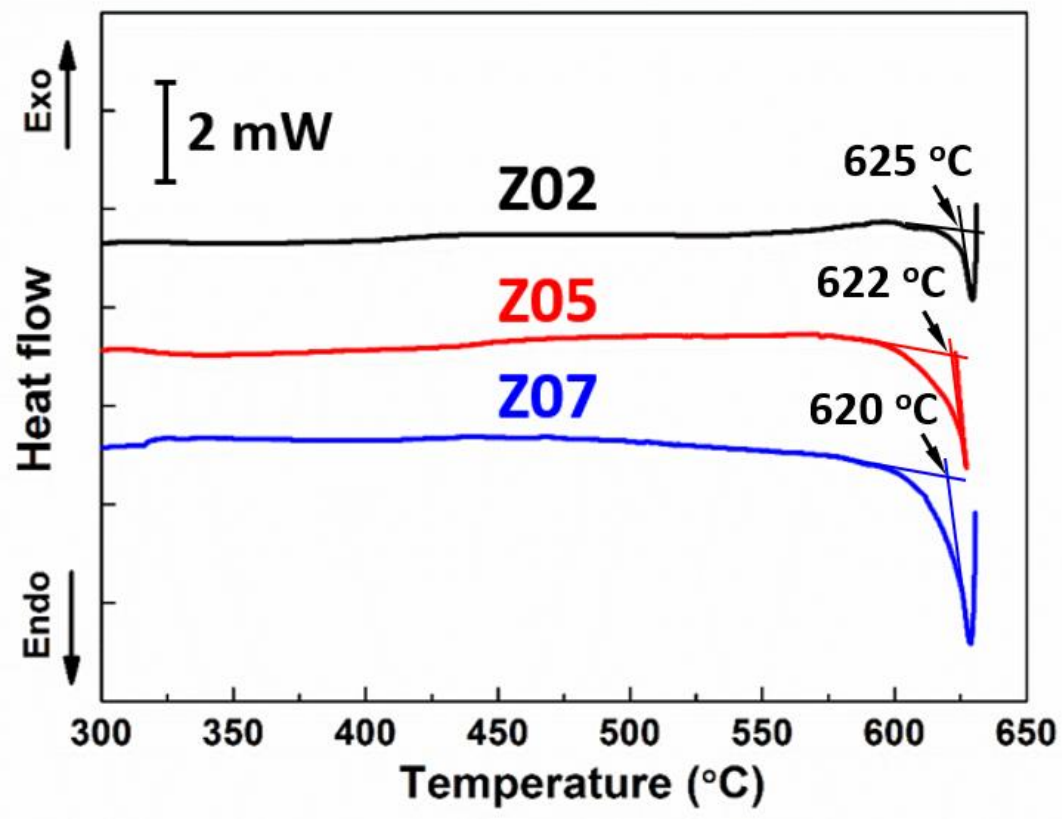

Fig. 3 DSC curves of the as-homogenized dilute alloys. 
Fig. 4

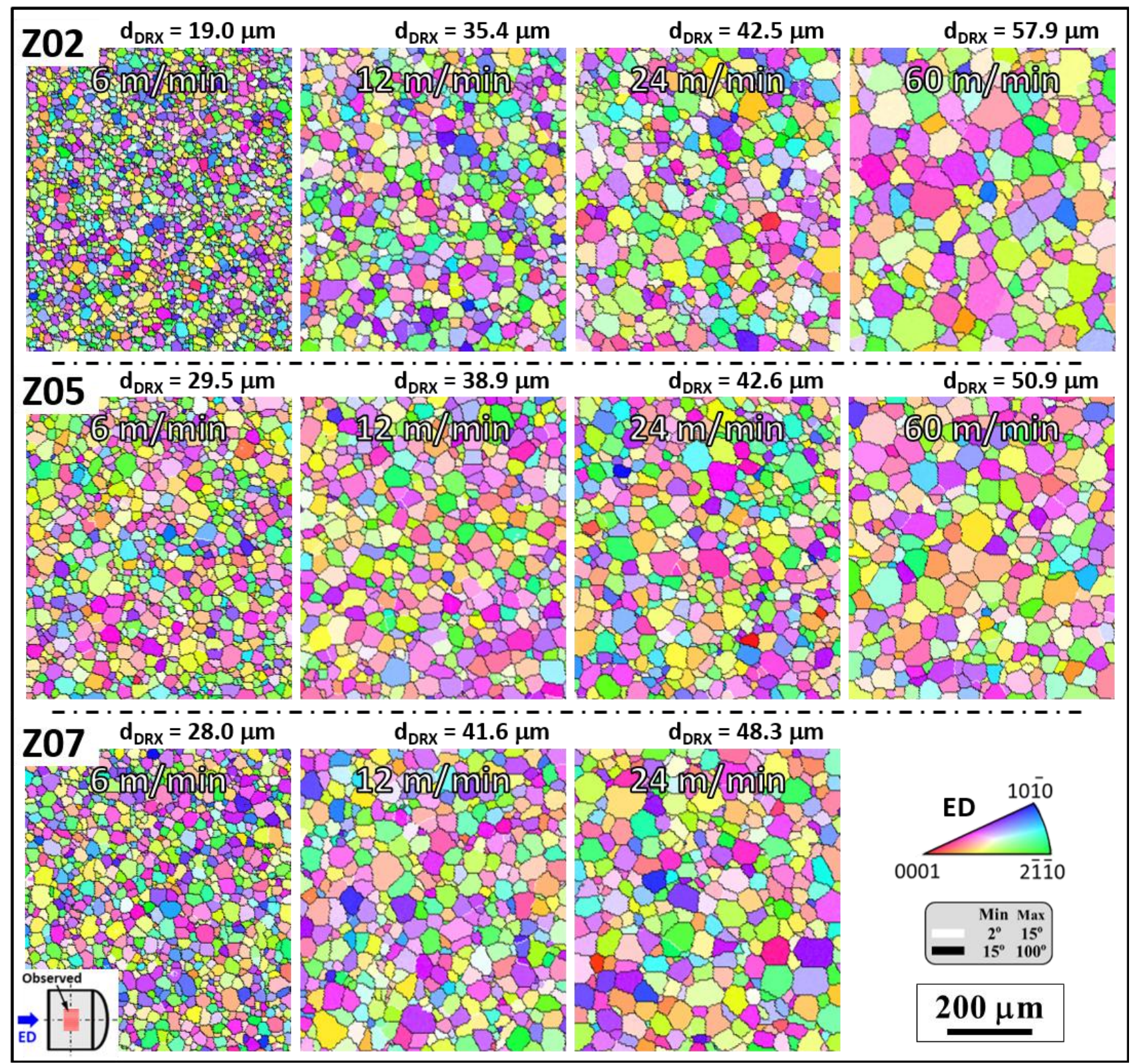

Fig. 4 Inverse pole figure maps of the extruded dilute alloys. 
Fig. 5

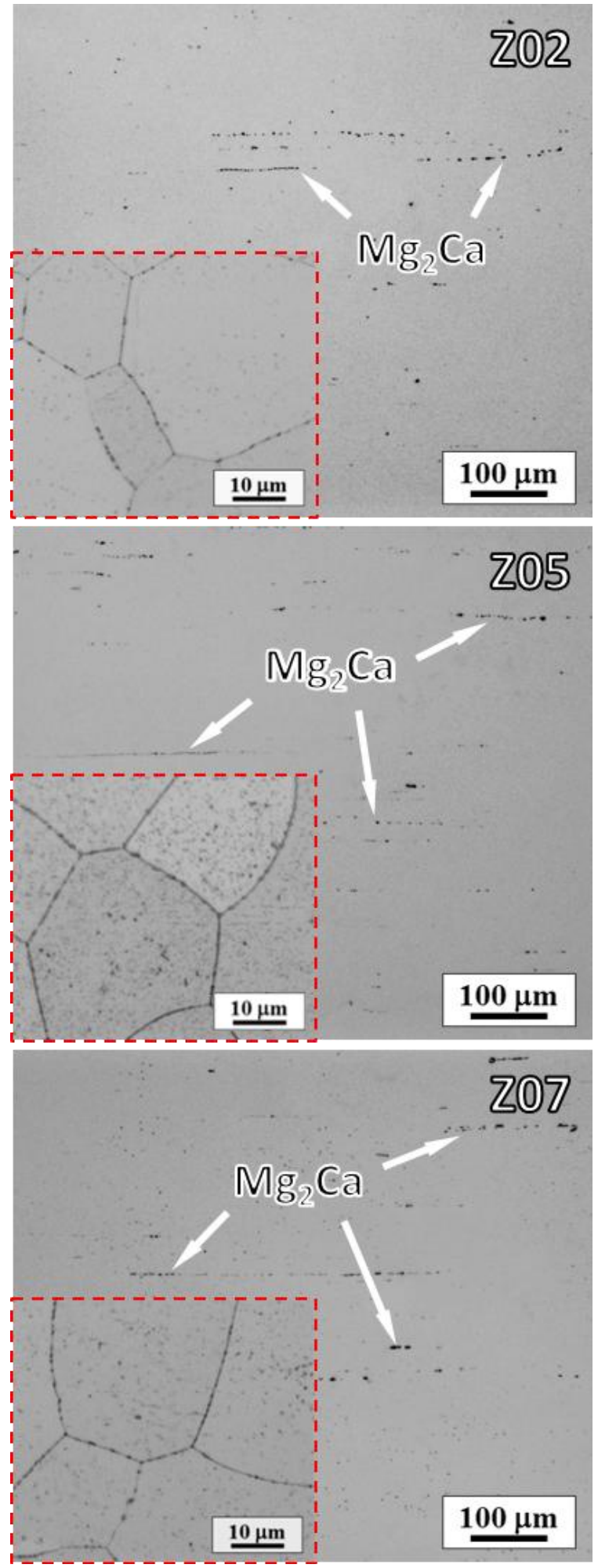

Fig. 5 Optical microstructures of the dilute alloys showing the distribution of second phase particles after extrusion at $24 \mathrm{~m} / \mathrm{min}$. Here, etched optical microstructures in red rectangular regions show fine dynamic precipitates distributing at DRXed GBs and within the grain interiors. 
Fig. 6

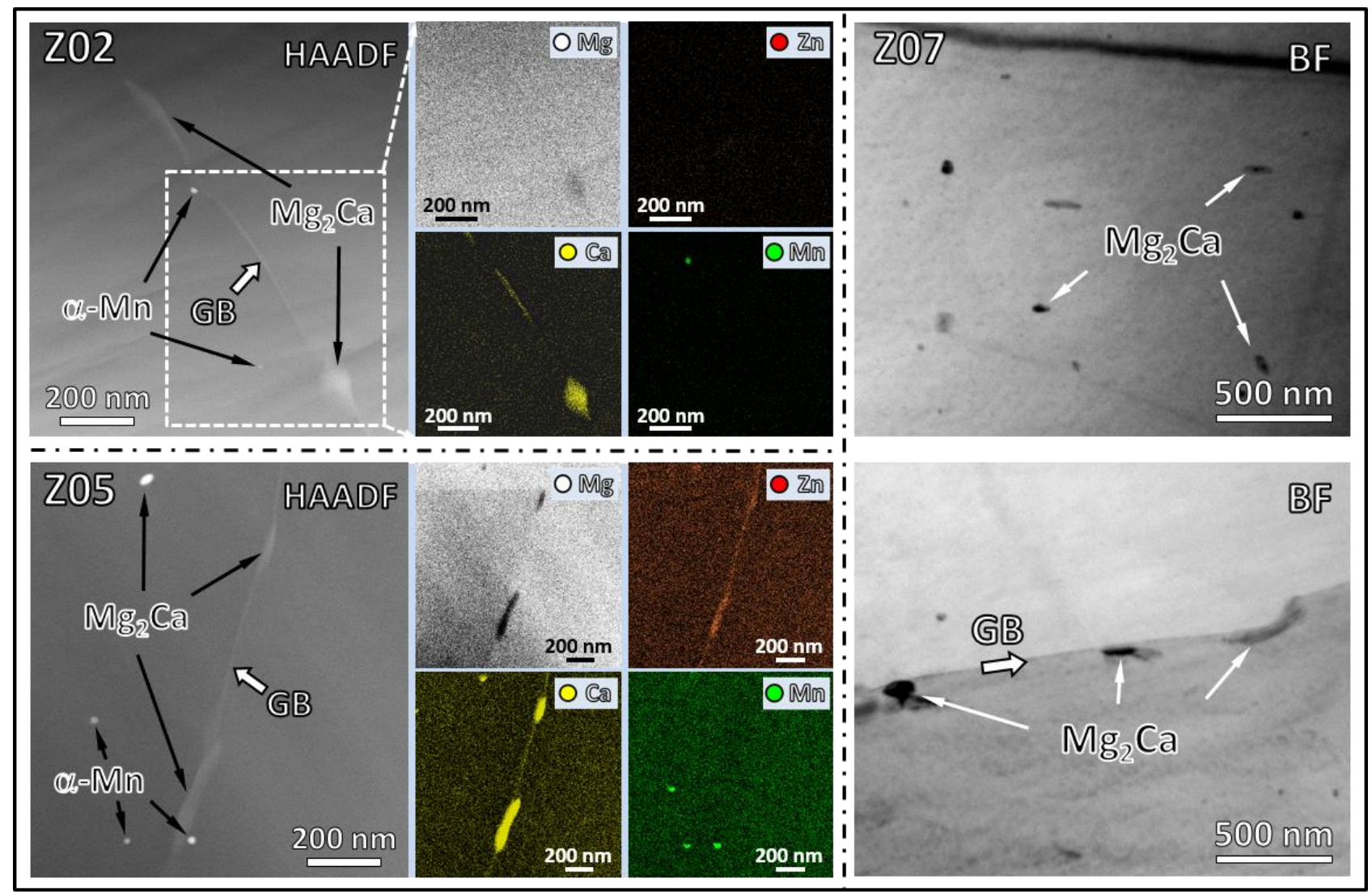

Fig. 6 TEM observation results of dynamic precipitates in the dilute alloys extruded at $24 \mathrm{~m} / \mathrm{min}$ : HAADF images and the corresponding EDX elemental mappings of Z02 and Z05 alloys and TEM BF images of Z07 alloy. 
Fig. 7

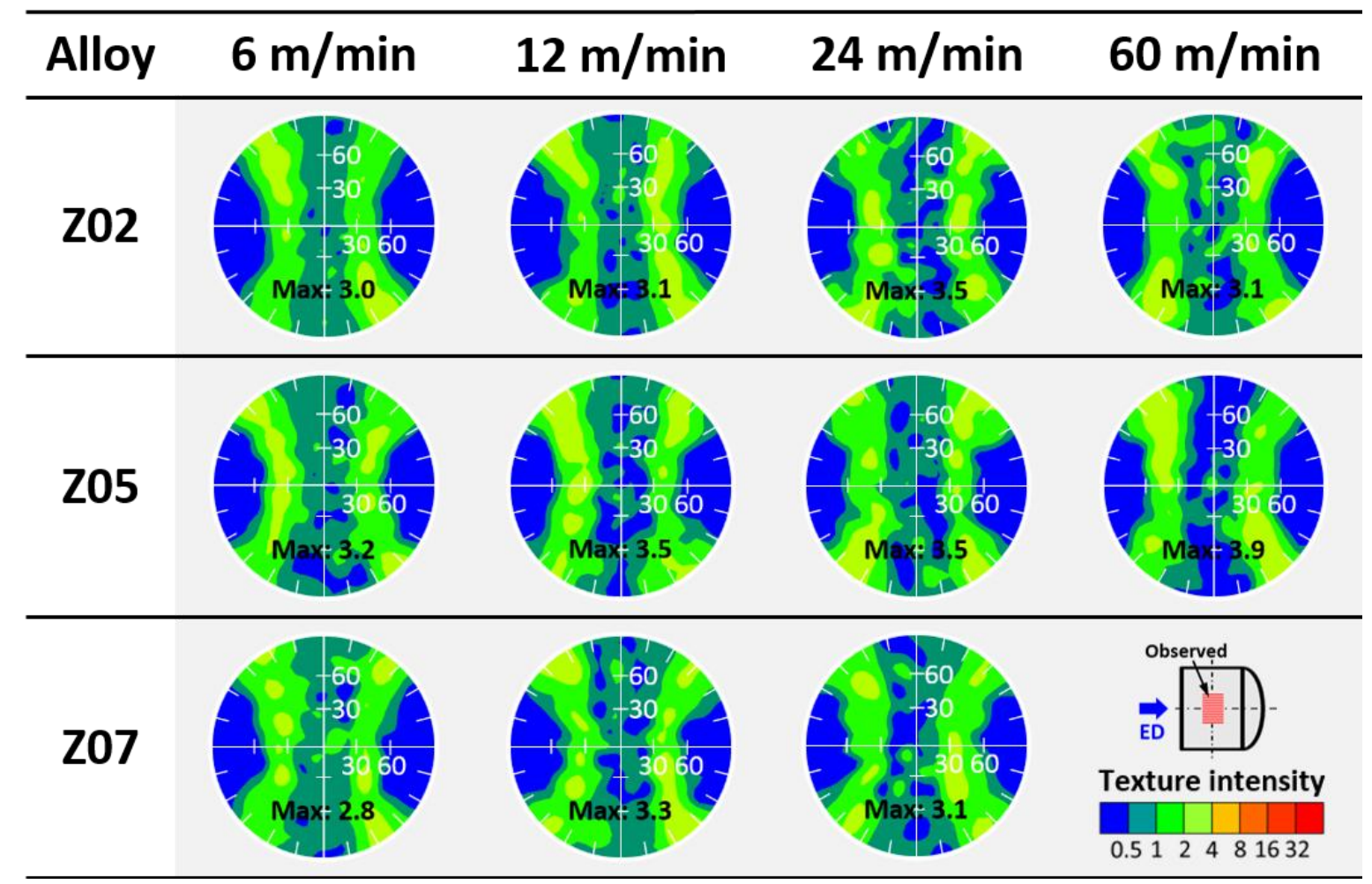

Fig. 7 (0001) pole figures of the extruded dilute alloys.

Fig. 8

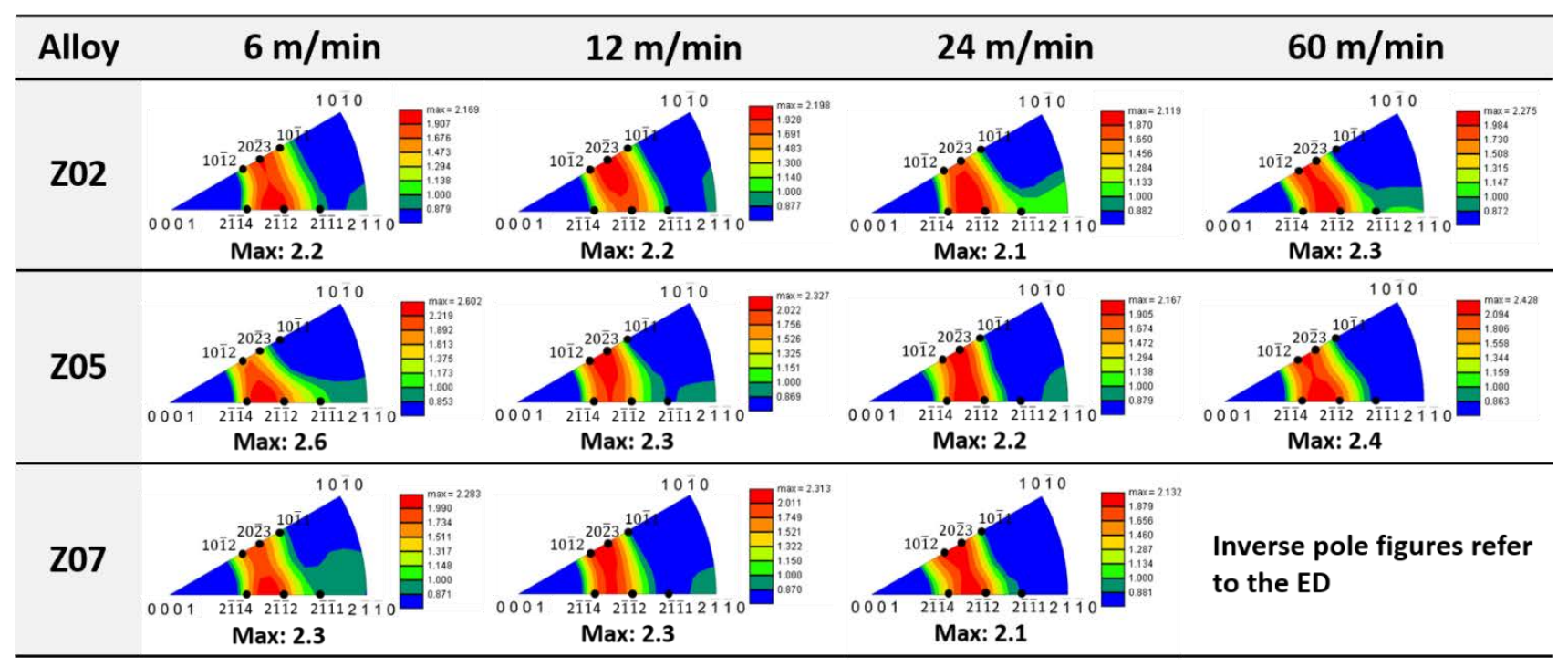

Fig. 8 Inverse pole figures referring to the ED of the extruded dilute alloys. 
Fig. 9

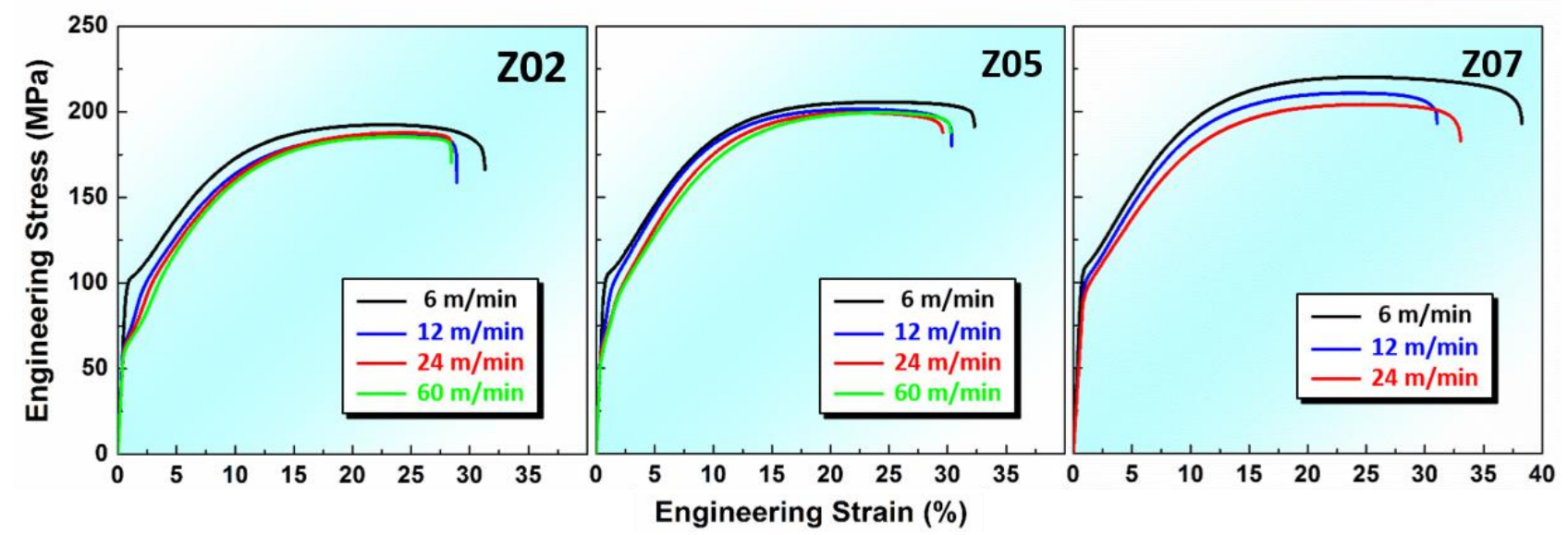

Fig. 9 Room temperature engineering stress-strain curves of the extruded dilute alloys.

Fig. 10

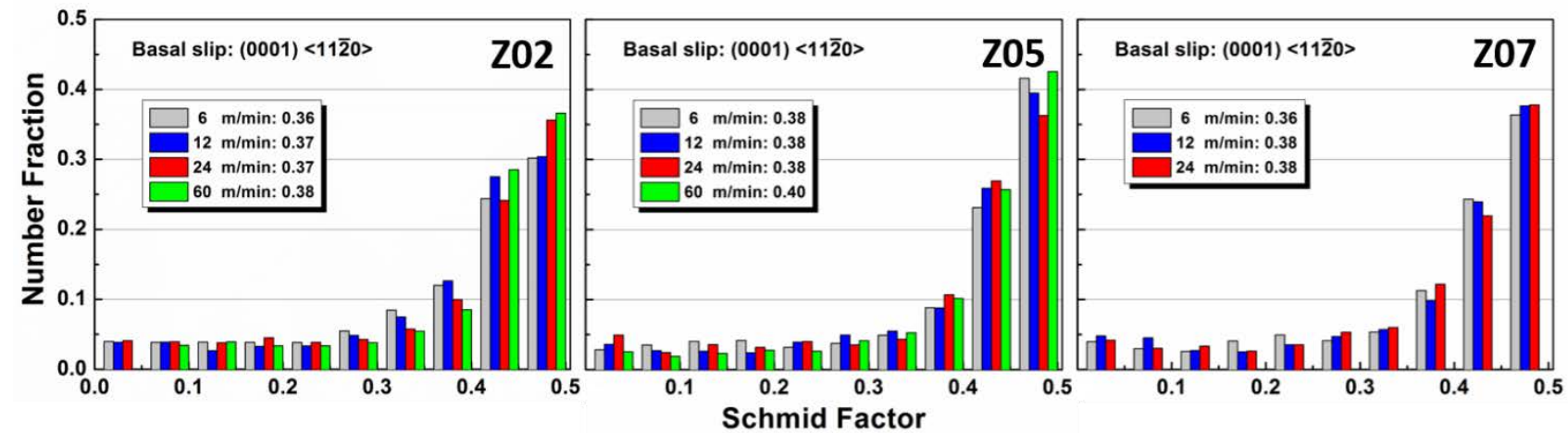

Fig. $10(0001)<11-20>$ basal slip Schmid factor distribution histograms of the extruded dilute alloys when the tensile stress is applied along the ED. 
Fig. 11

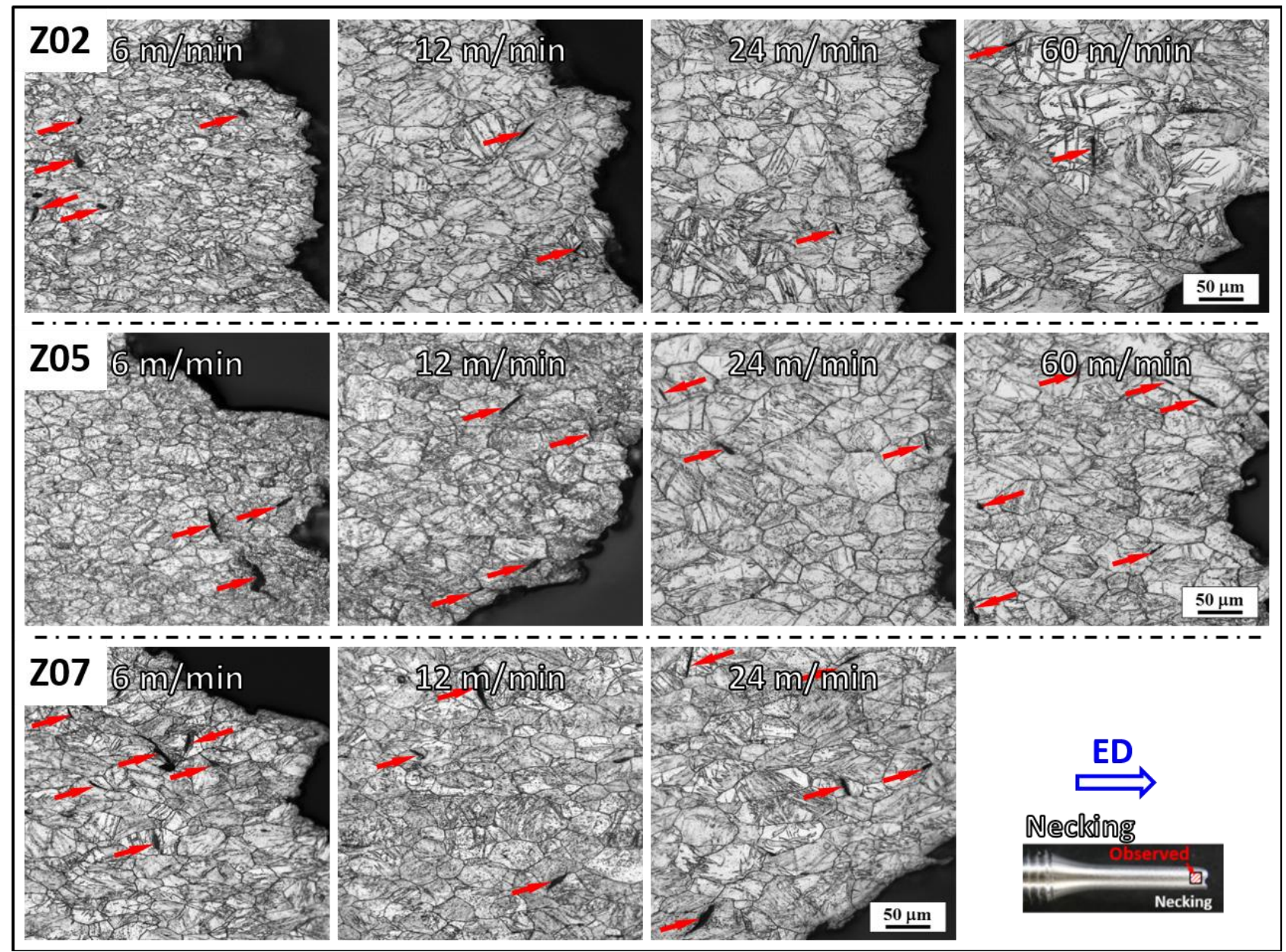

Fig. 11 Optical microstructures of fractured tensile specimens of the extruded dilute alloys. The red arrows indicate the microcracks initiated along the twins. 
Table. 1

Analyzed chemical compositions of the investigated alloys (wt.\%).

\begin{tabular}{ccccc}
\hline Alloy designation & Zn & Ca & Mn & Mg \\
\hline Z02 & 0.21 & 0.30 & 0.14 & Bal. \\
Z05 & 0.53 & 0.24 & 0.27 & Bal. \\
Z07 & 0.71 & 0.36 & 0.07 & Bal. \\
\hline
\end{tabular}

Table. 2

The measured volume fraction $(f)$ and average radius $(r)$ of second phase particles, and calculated Zener limited grain diameter $(D z)$ for Z07 alloy after extrusion at $24 \mathrm{~m} / \mathrm{min}$.

\begin{tabular}{cccc}
\hline Second phase & $f(\%)$ & $r(\mathrm{~nm})$ & $D z(\mu \mathrm{m})$ \\
\hline Fine dynamic precipitate & 1.1 & 48.1 & 5.8 \\
Large $\mathrm{Mg}_{2}$ Ca particle & 0.2 & 290.3 & 1935.3 \\
\hline
\end{tabular}

